\title{
Cooling and Wetting Effects of Agricultural Development on Near-Surface Atmosphere over Northeast China
}

\author{
Nana Zhao, ${ }^{1,2}$ Songjun Han, ${ }^{1,3}$ Di Xu, ${ }^{1,3}$ Jiandong Wang, ${ }^{1,3}$ and Hongjing Yu ${ }^{1}$ \\ ${ }^{1}$ State Key Laboratory of Simulation and Regulation of Water Cycle in River Basin, China Institute of Water Resources and \\ Hydropower Research, Beijing 100038, China \\ ${ }^{2}$ Institute of Wetland Research, Chinese Academy of Forestry, No. 1 Dongxiaofu Road, Haidian District, Beijing 100091, China \\ ${ }^{3}$ National Center of Efficient Irrigation Engineering and Technology Research, Beijing 100048, China
}

Correspondence should be addressed to Songjun Han; hansj@iwhr.com

Received 16 August 2016; Revised 27 October 2016; Accepted 3 November 2016

Academic Editor: Zhenghui Xie

Copyright (C) 2016 Nana Zhao et al. This is an open access article distributed under the Creative Commons Attribution License, which permits unrestricted use, distribution, and reproduction in any medium, provided the original work is properly cited.

\begin{abstract}
The effects of agricultural development on observed changes in near-surface atmospheric temperature and moisture from 1960 to 2014 over Northeast China are evaluated using data from 109 meteorological stations. Cultivated land fraction (CF) within a $3 \mathrm{~km}$ radius of the meteorological station is used as a quantitative indicator of agricultural intensity. Stations with large CFs experience a less significant increase in air temperature, especially in daily maximum temperature $\left(T_{\max }\right)$ and a more rapid increase in vapor pressure $\left(e_{a}\right)$ and relative humidity $(\mathrm{RH})$ than stations with small CFs, especially during the main growing season (from May to September). Compared with the reference station group with $\mathrm{CF}<0.2$, cooling effects during May to September in terms of daily mean, maximum, and minimum temperature by $-0.067^{\circ} \mathrm{C},-0.081^{\circ} \mathrm{C}$, and $-0.069^{\circ} \mathrm{C}$ per decade and wetting effects of May to September regarding $e_{a}$ by $0.075 \mathrm{hPa}$ and $\mathrm{RH}$ by $0.56 \%$ per decade exist for the station group with $\mathrm{CF}>0.5$. The cooling and wetting effects can be attributed to the agricultural development and thus should be considered when analyzing the near-surface atmospheric temperature and moisture records in Northeast China.
\end{abstract}

\section{Introduction}

Agricultural activities, including the conversion of rainfed to irrigated land and the enhancement of irrigation or fertilization, may increase vegetation activities [1] and alter the energy partitioning between sensible heat and latent heat [2]. Agricultural development-induced increase in evapotranspiration would lower the near-surface air temperature $[1,3-5]$ and lead to additional water vapor into the nearsurface atmosphere $[6,7]$. The effects of agricultural development on climate have been investigated over almost all the main agricultural areas of the world [5, 7-10], especially about the irrigation effects on the land surface fluxes [11$14]$, temperature [15, 16], atmospheric moisture content [17], cloud $[18,19]$ and precipitation $[20,21]$, and so forth.

Previous studies, for both simulations and observations, have shown that the agricultural development, especially irrigation expansion in cropland regions, exerts significant cooling and wetting effects on near-surface atmosphere regardless of their climate regime [5, 22-26]. Observational studies typically rely on pairwise comparisons of the changes in temperature, water vapor pressure, relative humidity, or dewpoint temperature $[5,7,17]$ between agricultural and nonagricultural locations. As an example, a study in California has revealed a highly significant effect of irrigation on summer average maximum temperature, with substantial $5.0^{\circ} \mathrm{C}$ cooling for $100 \%$ irrigation cover [5, 25]. Comparatively, the agricultural development-induced cooling effect is more obvious on the maximum temperature [17, 27]. As discussed by Gaffen and Ross [28], the considered evapotranspiration from irrigation may be one of the possible causes for the increase in observed near-surface humidity over the United States. The cooling and wetting effects always accompany agricultural development, especially in boreal summer with crop growth. A study in the Great Plains of North America has revealed that irrigated agriculture development has modified the near-surface atmospheric temperature and moisture 
records in irrigated locations and resulted in a decrease in the mean maximum temperatures during the growing season [29] and an increase in near-surface atmospheric moisture content [17, 30]. Observational studies also have indicated that irrigation had cooling effects on local temperature [7] and wetting effects on atmospheric moisture content [31] in the growing season over Xinjiang, Northwest of China.

Benefiting from the expanded irrigation, increased fertilizers using, and improved crop management, China experienced remarkable agricultural development since the 1960s. The irrigated area in China increased from $30.1 \times 10^{6}$ ha in 1961 to $63.5 \times 10^{6}$ ha in 2013 , with more rapidly expansion in the northern region. Meanwhile, the effects of irrigation on climate have been investigated over Northern China: from the arid Northwest region [7, 31] and the Yellow River Basin $[32,33]$ to the Huang-Huai-Hai Plain $[34,35]$. As a main agricultural area in China, Northeast China has undergone rapid cropland extension in the last century, where the cropland area increased from $9.8 \%$ of Northeast China area in 1908 to $29.6 \%$ in 2000 [36]. Studies in this area have paid significant attention to the effect of climate change on food production [37] and agriculture expansion [38]. The changes of near-surface temperature and moisture would contribute to changes of evaporation demand [39], which require comprehensive understanding. In the past 50 years, significant warming trends [40] had been accompanied by land cover change $[38,41]$, which had created favorable conditions for agriculture development. However, a significant warming and a slight decreasing in precipitation had also been accompanied in this region [42], which might result in increasing irrigation water requirement. A large irrigation project aiming to increase food production is conducting in Northeast China since 2012, in which the irrigated area will be expanded by $2.53 \times 10^{6}$ ha after the project. Observational evidence of cooling effects with irrigation expansion was found according to the comparison of two rainfed and two irrigated sites in this region [43].

Although the impressions that agricultural development would affect observed air temperature and atmospheric moisture have been acknowledged, the extent of their contributions on temperature and moisture records over Northeast China with a boreal climate remains elusive. The objective of this study is to quantitatively investigate the effects of agricultural development on observed temperature and atmospheric moisture changes in Northeast China.

\section{Study Area, Data, and Methods}

2.1. Study Area. Northeast China $\left(38^{\circ} 42^{\prime} \mathrm{N}\right.$ to $53^{\circ} 36^{\prime} \mathrm{N}$, $115^{\circ} 24^{\prime} \mathrm{E}$ to $135^{\circ} 12^{\prime} \mathrm{E}$ ) covers Heilongjiang, Jilin, and Liaoning provinces, as well as the eastern part of the Inner Mongolia Autonomous Region (Figure 1), with an area of $1.23 \times 10^{6} \mathrm{~km}^{2}$ (12.8\% of China in its entirety), of which nearly $30 \%$ is arable $[36,41]$. The topography is dominated by a few mountain ranges, such as the Greater Khingan and the Lesser Khingan. The low-lying terraces formed by the Heilong River and the Ussuri River are the most food productive land, where most of the farmland are transferred from wetlands [38]. The mean annual precipitation decreases from southeastern to northwestern [44], ranging from $1000 \mathrm{~mm}$ in the southeastern Changbai Mountains to $300 \mathrm{~mm}$ in the Inner Mongolia Plateau [45]. Most precipitation occurred during summer ( $65.7 \%$ of annual precipitation). The main crops in this region are rice, soybean, spring maize, and wheat. The dry spring results in water stress in the initial growing season, and supplemental irrigation is essential to ensure the grain product [46, 47]. At present, the gross irrigation amount per unit area is $6.4 \times 10^{3} \mathrm{~m}^{3} /$ ha. Surface water is the main source for irrigation. However, the increasing groundwater withdrawal for irrigation has resulted in serious groundwater crisis in regions with primarily groundwater-fed irrigation.

As one of the important food bases in China, the study area plays an extremely important and irreplaceable role in the national food security and had presented a rapid agricultural development from 1960 to 2014. Taking the Heilongjiang, Jilin, and Liaoning provinces into account, the total grain production also exhibited a rapid rise under agricultural development, from $128.9 \times 10^{4}$ tons in 1960 to $1152.9 \times 10^{4}$ tons in 2014 (Figure 2). The agricultural cultivated area increased by $628.2 \times 10^{4}$ ha from 1960 to 2014. The area equipped for irrigation had also experienced a significant increase from $196.2 \times 10^{4}$ ha in 1960 to $840.8 \times$ $10^{4}$ ha in 2014 , especially a sharp increase since the late $1990 \mathrm{~s}$.

2.2. Data and Methods. The data used in this study includes the daily average temperature $\left(T_{a}\right)$, maximum temperature $\left(T_{\max }\right)$, minimum temperature $\left(T_{\min }\right)$, diurnal temperature range (DTR) $\left(T_{\max }-T_{\min }\right)$, and relative humidity $(\mathrm{RH})$ from 1960 to 2014 of stations across Northeast China. The water vapor pressure $\left(e_{a}, \mathrm{hPa}\right)$ was calculated according to $T_{\max }$, $T_{\min }$, and $\mathrm{RH}$, as referred to by Allen et al. [48], as follows:

$$
e_{a}=\frac{\mathrm{RH}}{100} \frac{6.108 \exp \left(17.27 T_{\max } /\left(T_{\max }+237.3\right)\right)+6.108 \exp \left(17.27 T_{\min } /\left(T_{\min }+237.3\right)\right)}{2}
$$

The meteorological data were provided and quality-tested by the National Meteorological Information Center of the China Meteorological Administration http://data.cma.cn/. The stations with time series of less than 30 years were excluded. After the data were filtered for missing observations, a total of 109 stations remained (Figure 1).
Land use data for 2000, in which the area proportions of cultivated land, forest, residential, industrial, and traffic lands were provided at grid intervals of $1 \mathrm{~km}$, were obtained from the Data Center for Resources and Environmental Sciences of the Chinese Academy of Sciences [49]. The area fractions of the cultivated lands in 2000 are shown 


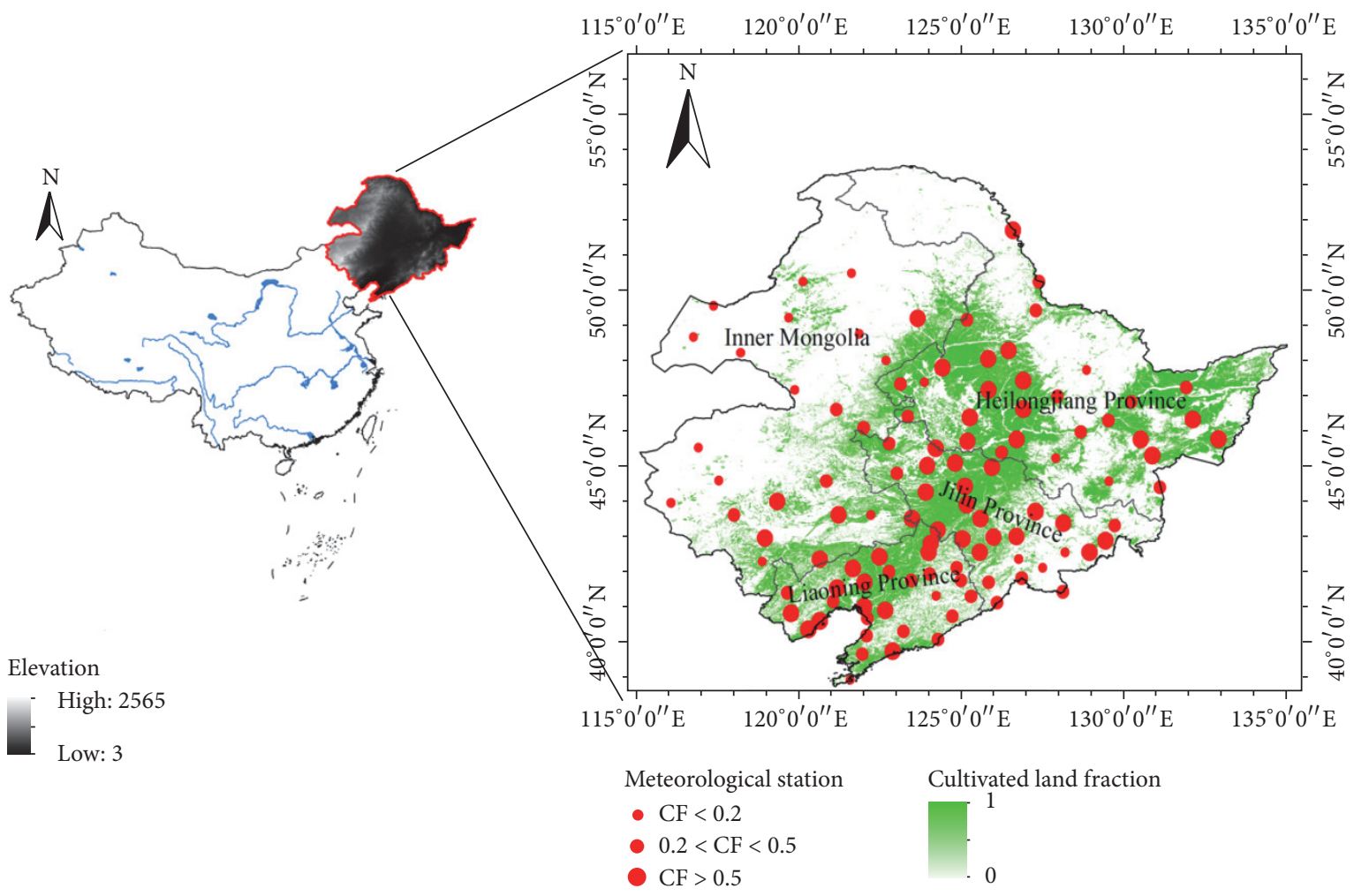

FIGURE 1: Location of the study area and meteorological stations.

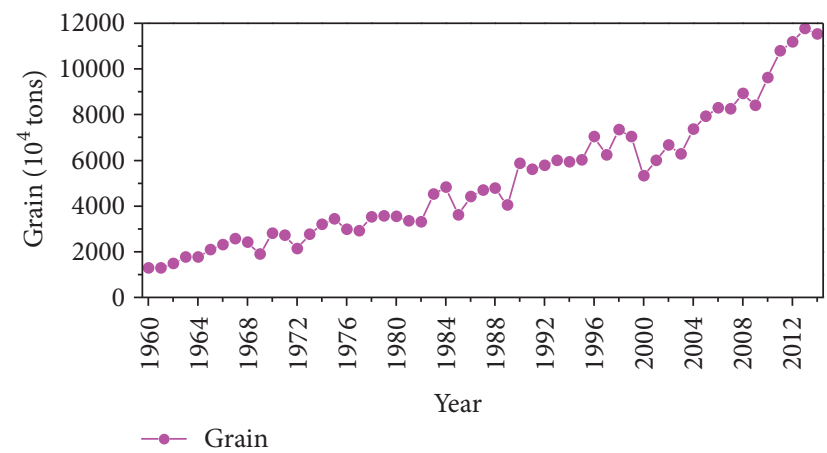

(a)

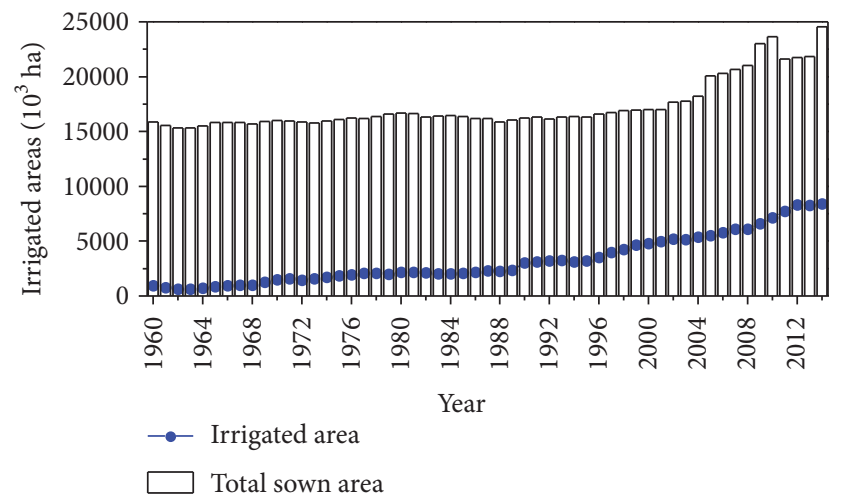

(b)

FIGURE 2: Time series of total (a) grains production and crops sown area and irrigated area of Heilongjiang, Jilin, and Liaoning provinces from 1960 to 2014.

in Figure 1. The 109 stations are located in landscapes with markedly different cultivated land uses. The cultivated land fractions (CFs) within radii of $1 \mathrm{~km}$ to $10 \mathrm{~km}, 15 \mathrm{~km}$, and $30 \mathrm{~km}$, centered at each station, were used to evaluate the intensity of cultivated land uses. According to the CFs within a $3 \mathrm{~km}$ radius of each station, the 109 stations (with CFs ranging from $0 \%$ to $91.4 \%$ ) could be classified into three groups in this study; namely, 23 were characterized by $\mathrm{CF}<$ $0.2(\mathrm{CF}=0$ for 9 of these stations), 37 by $0.2<\mathrm{CF}<0.5$, and 49 by $0.5<\mathrm{CF}<0.9$. The stations with $\mathrm{CF}<0.2$ (average $\mathrm{CF}=0.06$ ) are mainly located in the north and west mountainous regions with an insignificant agricultural influence. The stations with intensive cultivated land uses $(\mathrm{CF}>0.5$, average $\mathrm{CF}=0.65)$ are mainly located in the central region with abundant water supply for irrigation. The mean annual precipitation for stations with $\mathrm{CF}>0.5$ is only $539.3 \mathrm{~mm}$ (Table 1$)$ ( $453.9 \mathrm{~mm}$ during the growing season). Crop water requirement cannot be supplied by 
TABLE 1: General conditions of the stations and yearly average temperature $\left(T_{a},{ }^{\circ} \mathrm{C}\right)$, maximum temperature $\left(T_{\max },{ }^{\circ} \mathrm{C}\right)$, minimum temperature $\left(T_{\min },{ }^{\circ} \mathrm{C}\right)$, mean water vapor pressure $\left(e_{a}, \mathrm{hPa}\right)$, relative humidity $(\mathrm{RH}, \%)$, and precipitation $(P, \mathrm{~mm})$ in all of the months, from May to September and from October to April, for the station groups with different cultivated land fractions.

\begin{tabular}{lccc}
\hline & & Groups with different cultivated land fraction \\
& CF $<0.2$ & $0.2<\mathrm{CF}<0.5$ & CF $>0.5$ \\
Number of stations & 23 & 37 & 49 \\
Elevation (m) & & & 209.7 \\
$\quad$ Average & 541.1 & 225.8 & 634.3 \\
$\quad$ max & 1003 & 799.5 & 4.8 \\
$\quad$ min & 91.5 & 3.8 & $65 \%$ \\
Average cultivated land fraction & $6 \%$ & $37 \%$ & 5.29 \\
Annual climate characteristics & & & 11.42 \\
$T_{\text {ave }}$ & 2.29 & 5.33 & -0.26 \\
$T_{\max }$ & 8.97 & 11.64 & 8.51 \\
$T_{\min }$ & -3.73 & -0.25 & 63.1 \\
$e_{a}$ & 7.02 & 8.58 & 64.2 \\
RH & 63.7 & 617.7 & 539.3 \\
$P$ & 475.1 & & \\
\hline
\end{tabular}

precipitation during the growth period. Taking the paddy rice as an example, the water requirement ranges from $250 \mathrm{~mm}$ to $750 \mathrm{~mm}$, with irrigation requirement from $80 \mathrm{~mm}$ to $450 \mathrm{~mm}$ [50]. Therefore, supplemental irrigation is needed to ensure grain production $[46,47]$.

Both parametric and nonparametric methods (e.g., the linear regression method and the Mann-Kendall test) are widely used to identify trends in the data. The nonparametric tests are more suitable for identifying the trends in the field of hydrology and meteorological study, where the nonnormally distributed, censored data, including missing values, are frequently encountered in these time series [51]. By contrast, the time series are required to be independent and normally distributed using parametric methods. The nonparametric Mann-Kendall test with a trend-free, prewhitening method [52] was widely used to identify temperature and atmosphere moisture trends $[31,43,53]$. Therefore it is used in this study.

The dependence of the trends in observed surface air temperature and atmospheric moisture content on CFs was evaluated on the basis of regression slopes and linear correlation coefficients according to the linear regressions of temperature and atmospheric moisture content trends on the CFs, following the method of Han et al. [7, 54]. The statistical significance of the correlation coefficient and linear regression was evaluated through a $t$-test. The CFs within radii of $1 \mathrm{~km}$ to $10 \mathrm{~km}, 15 \mathrm{~km}$, and $30 \mathrm{~km}$, centered at each station, were all tested. A certain radius generating the most significant correlations would be regarded as optimal and be selected as the index representing the intensity of agricultural development.

\section{Results}

3.1. Observed Temperature and Atmospheric Moisture Trends. The trends of yearly mean temperature $\left(T_{a}, T_{\max }, T_{\min }\right.$, and
TABLE 2: Average trends of temperature $\left(T_{a}, T_{\max }, T_{\min }\right.$, and DTR, $\left.{ }^{\circ} \mathrm{C}\right)$, mean water vapor pressure $\left(e_{a}, \mathrm{hPa}\right)$, and relative humidity $(\mathrm{RH}$, $\%)$ in annual, growing season, and nongrowing season.

\begin{tabular}{lcccccc}
\hline & $T_{a}$ & $T_{\max }$ & $T_{\min }$ & $\mathrm{DTR}$ & $e_{a}$ & $\mathrm{RH}$ \\
\hline Annual & 0.30 & 0.20 & 0.43 & -0.23 & 0.08 & -0.33 \\
Growing season & 0.24 & 0.19 & 0.35 & -0.17 & 0.12 & -0.36 \\
Nongrowing season & 0.35 & 0.21 & 0.49 & -0.29 & 0.05 & -0.29 \\
\hline
\end{tabular}

DTR) and atmospheric moisture $\left(e_{a}, \mathrm{RH}\right)$ in the growing season (from May to September), nongrowing season (from October to April), and all 12 months of the 109 stations from 1960 to 2014 are evaluated. The average annual trend slopes of $T_{a}, T_{\max }, T_{\min }, \mathrm{DTR}, e_{a}$, and RH are $0.30^{\circ} \mathrm{C} \cdot$ decade $^{-1}, 0.20^{\circ} \mathrm{C} \cdot$ decade $^{-1}, 0.43^{\circ} \mathrm{C} \cdot$ decade $^{-1}$, $-0.23^{\circ} \mathrm{C} \cdot$ decade $^{-1}, 0.08 \mathrm{hPa} \cdot$ decade $^{-1}$, and $-0.33 \% \cdot$ decade $^{-1}$, respectively (Table 2 ). Owing to the more significant increase in $T_{\min }$, DTR presents a decreasing trend, especially in the middle and south regions with large CFs. The air temperature in the growing season presents a less obvious increase than that in the nongrowing season, whereas the vapor pressure in the growing season presents a more significant increase than that in the nongrowing season (Table 2). For all stations, $106,90,108$, and 82 are significant at 95\% confidence level for the growing season in terms of $T_{a}, T_{\max }, T_{\min }$, and DTR, respectively. The trends in $e_{a}$ and $\mathrm{RH}$ in the growing season are significant at $95 \%$ confidence level for 66 and 54 of all stations, respectively.

The temperature trends during the growing season of stations in the north, mainly with mountainous terrain and small CF, are generally higher than those in middle and south regions with large CFs, especially for $T_{\max }$ (Figure 3). On the contrary, $e_{a}$ exhibits a more obvious increase, and $\mathrm{RH}$ indicates a less obvious decrease in the middle and southern 


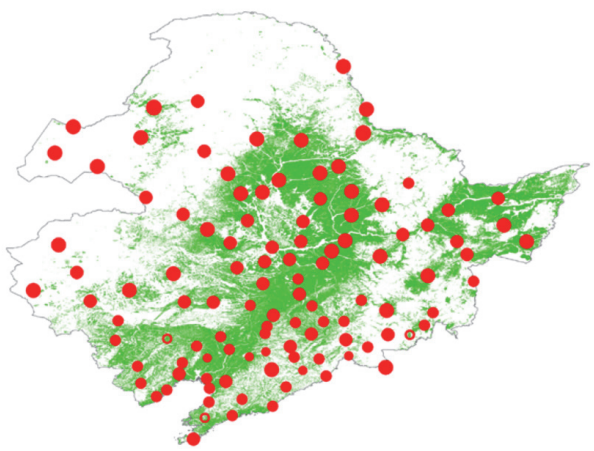

Trends in $T_{a}\left({ }^{\circ} \mathrm{C} /\right.$ decade $)$

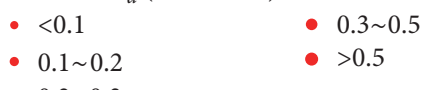

(a)

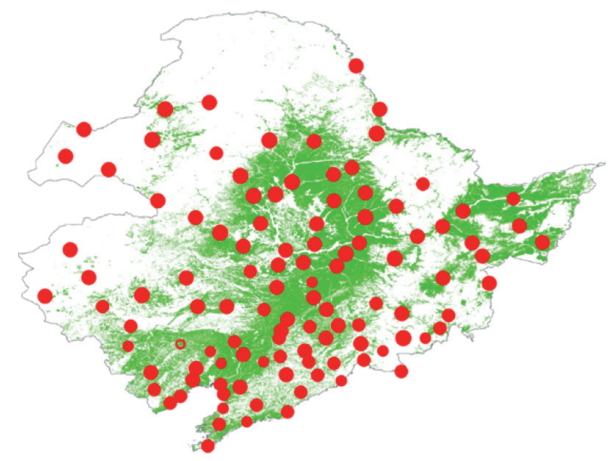

Trends in $T_{\min }\left({ }^{\circ} \mathrm{C} /\right.$ decade $)$

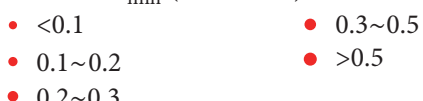

(c)

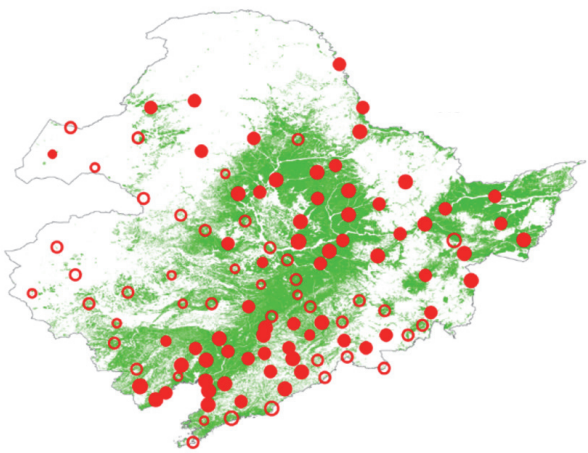

Trends in $e_{a}(\mathrm{hPa} /$ decade $)$

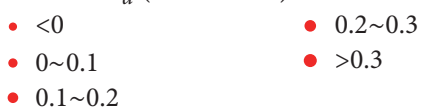

(e)

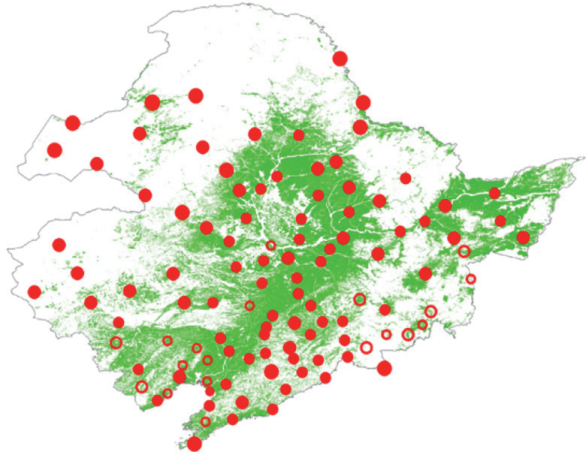

Trends in $T_{\max }\left({ }^{\circ} \mathrm{C} /\right.$ decade $)$
- $<0.1$
- $0.3 \sim 0.5$
- $0.1 \sim 0.2$
- $>0.5$

- $0.2 \sim 0.3$

(b)

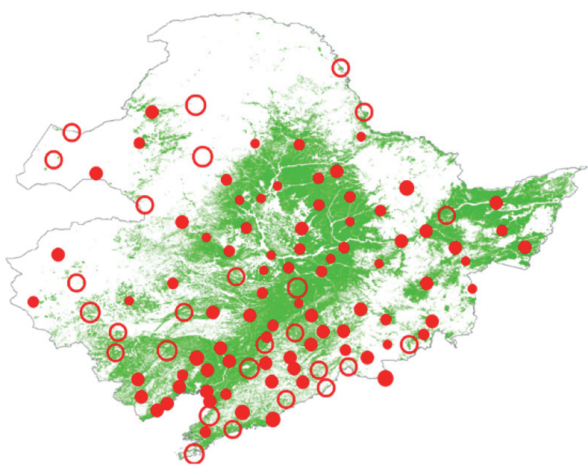

Trends in DTR $\left({ }^{\circ} \mathrm{C} /\right.$ decade $)$
- $<-0.3$
- $-0.1 \sim 0$
- $-0.3 \sim-0.2$
- $>0$

- $-0.2 \sim-0.1$

(d)

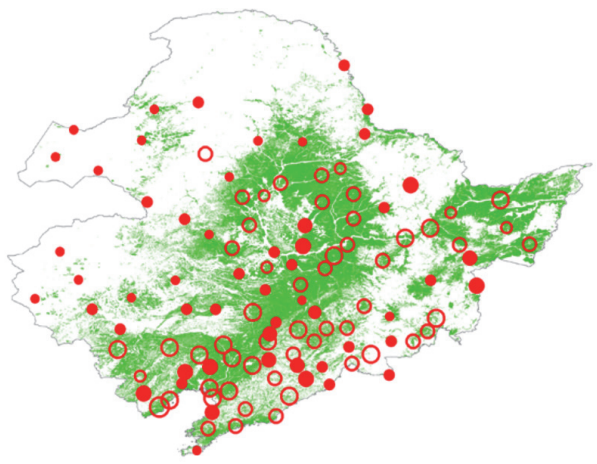

Trends in $\mathrm{RH}$ (\%/decade)

$$
\begin{array}{ll}
-<-1 & \bullet 0 \sim 0.5 \\
\text { - }-1 \sim-0.5 & \bullet>0.5 \\
\text { - }-0.5 \sim 0 &
\end{array}
$$

(f)

FIGURE 3: Spatial distribution of the trend slopes of (a) $T_{a}$, (b) $T_{\max }$, (c) $T_{\min }$, (d) DTR, (e) $e_{a}$, and (f) RH in growing season from 1960 to 2014. The solid marks indicate that the trends are significant at the $95 \%$ confidence level, and unfilled marks demonstrate that the trends are not significant at the $95 \%$ confidence level. 
TABLE 3: Correlation coefficients for trends in $T_{a}, T_{\max }, T_{\min }$, DTR, $e_{a}$, and RH with cultivated land fraction within a specific radius of each station.

\begin{tabular}{|c|c|c|c|c|c|c|}
\hline \multirow{2}{*}{ Radii (km) } & \multicolumn{6}{|c|}{ Growing season } \\
\hline & $T_{a}$ & $T_{\max }$ & $T_{\min }$ & DTR & $e_{a}$ & $\mathrm{RH}$ \\
\hline 1 & -0.13 & $-0.24^{*}$ & -0.13 & -0.07 & 0.14 & $0.23^{*}$ \\
\hline 2 & $-0.21^{*}$ & $-0.34^{* *}$ & $-0.17^{\#}$ & -0.11 & $0.28^{* *}$ & $0.37^{* *}$ \\
\hline 3 & $-0.24^{*}$ & $-0.39^{* *}$ & $-0.17^{\#}$ & $-0.16^{\#}$ & $0.30^{* *}$ & $0.40^{* *}$ \\
\hline 4 & $-0.20^{*}$ & $-0.38^{* *}$ & -0.12 & $-0.21^{*}$ & $0.30^{* *}$ & $0.38^{* *}$ \\
\hline 5 & $-0.19^{*}$ & $-0.38^{* *}$ & -0.1 & $-0.23^{*}$ & $0.30^{* *}$ & $0.37^{* *}$ \\
\hline 6 & $-0.18^{\#}$ & $-0.38^{* *}$ & -0.08 & $-0.25^{* *}$ & $0.30^{* *}$ & $0.36^{* *}$ \\
\hline 7 & $-0.16^{\#}$ & $-0.38^{* *}$ & -0.06 & $-0.27^{* *}$ & $0.30^{* *}$ & $0.35^{* *}$ \\
\hline 8 & -0.15 & $-0.37^{* *}$ & -0.05 & $-0.28^{* *}$ & $0.30^{* *}$ & $0.35^{* *}$ \\
\hline 9 & -0.14 & $-0.37^{* *}$ & -0.05 & $-0.28^{* *}$ & $0.29^{* *}$ & $0.33^{* *}$ \\
\hline 10 & -0.12 & $-0.35^{* *}$ & -0.03 & $-0.28^{* *}$ & $0.27^{* *}$ & $0.32^{* *}$ \\
\hline 15 & -0.08 & $-0.32^{* *}$ & 0.01 & $-0.31^{* *}$ & $0.25^{* *}$ & $0.27^{* *}$ \\
\hline 30 & -0.04 & $-0.29^{* *}$ & 0.03 & $-0.31^{* *}$ & $0.25^{* *}$ & $0.26^{* *}$ \\
\hline
\end{tabular}

${ }^{* *}$ The regression exceeds the $99 \%$ confidence level. ${ }^{*}$ The regression exceeds the $95 \%$ confidence level. ${ }^{\#}$ The regression exceeds the $90 \%$ confidence level.

TABLE 4: Parameters of linear regression of the trends in $T_{a}, T_{\max }, T_{\min }, \mathrm{DTR}\left({ }^{\circ} \mathrm{C} \cdot \mathrm{decade}^{-1}\right), e_{a}\left(\mathrm{hPa} \cdot \mathrm{decade}{ }^{-1}\right)$, and $\mathrm{RH}\left(\% \cdot \mathrm{decade}{ }^{-1}\right)$ during 1960-2014 upon the CFs. The slope indicates a change in the trends associated with a $100 \% \mathrm{CF}$.

\begin{tabular}{lccccc}
\hline & \multicolumn{2}{c}{ Annual } & \multicolumn{2}{c}{ May-Sep. } & \multicolumn{2}{c}{ Oct.-Apr. } \\
& $k$ & $r$ & $k$ & $r$ & $-0.24^{*}$ \\
\hline$T_{a}$ & $-0.07 \pm 0.03$ & $-0.19^{*}$ & $-0.10 \pm 0.04$ & $-0.02 \pm 0.04$ \\
$T_{\max }$ & $-0.11 \pm 0.03$ & $-0.35^{* *}$ & $-0.14 \pm 0.03$ & $-0.39^{* *}$ & $-0.05 \pm 0.03$ \\
$T_{\min }$ & $-0.06 \pm 0.06$ & -0.11 & $-0.10 \pm 0.05$ & $-0.17^{\#}$ & $-0.01 \pm 0.07$ \\
DTR & $-0.06 \pm 0.06$ & -0.09 & $-0.08 \pm 0.05$ & $-0.16^{\#}$ & $-0.04 \pm 0.07$ \\
$e_{a}$ & $0.07 \pm 0.02$ & $0.30^{* *}$ & $0.13 \pm 0.04$ & $0.30^{* *}$ & -0.02 \\
RH & $0.72 \pm 0.18$ & $0.36^{* *}$ & $0.98 \pm 0.22$ & $0.40^{* *}$ & $-0.06 \pm 0.01$ \\
$P$ & $2.05 \pm 3.41$ & 0.06 & $2.34 \pm 3.29$ & 0.07 & $0.52 \pm 0.19$ \\
\hline
\end{tabular}

${ }^{* *}$ The regression exceeds the $99 \%$ confidence level. ${ }^{*}$ The regression exceeds the $95 \%$ confidence level. ${ }^{*}$ The regression exceeds the $90 \%$ confidence level.

regions. The near-surface air temperature and atmospheric moisture trends of the 109 stations are significantly correlated with the CFs within radii of $1 \mathrm{~km}$ to $10 \mathrm{~km}, 15 \mathrm{~km}$, and $30 \mathrm{~km}$, and the correlations are significant during the growing season (Table 3). Stations with large CFs are likely to experience less significant near-surface atmospheric warming and more significant wetting than stations with small CFs. Although the correlations are essentially the same for different radii, CFs within a $3 \mathrm{~km}$ radius of each station are used to denote the extent of agricultural land use thereafter because they are the most significant.

The trends of $T_{a}, T_{\max }, T_{\min }$, and DTR decreased with increasing CFs, especially during the growing season (Table 4). The correlation between $T_{\max }$ trends and CFs is the most significant $(P<0.01, n=109)$, and $T_{\min }$ and DTR trends are only significant in the growing season with 90\% confidence level. In October to April, no significant correlation is found, except for a weak correlation in $T_{\max }$ trends $(P<0.1, n=109)$. The trends of $T_{a}, T_{\max }, T_{\min }$, and DTR in the growing season are expected to decrease by $0.10^{\circ} \mathrm{C} \cdot$ decade $^{-1}, 0.14^{\circ} \mathrm{C} \cdot$ decade $^{-1}, 0.10^{\circ} \mathrm{C} \cdot$ decade $^{-1}$, and $0.08^{\circ} \mathrm{C} \cdot$ decade $^{-1}$, respectively, with full-covered cultivated land use (i.e., 100\% CF) (Figure 4). The $e_{a}$ and RH trends of all the 109 stations have high positive correlations with the CFs (at 99\% confidence level, except the nongrowing season $e_{a}$, which is at $95 \%$ confidence level) (Table 4 ). With the fullcovered cultivated land use (i.e., $100 \% \mathrm{CF}$ ), the $e_{a}$ trends in annual mean, growing season, and nongrowing season are expected to increase by $0.07,0.13$, and $0.02 \mathrm{hPa} \cdot \mathrm{decade}^{-1}$, respectively. Meanwhile, the trends in annual mean, growing season, and nongrowing season $\mathrm{RH}$ are expected to increase by $0.72,0.98$, and $0.52 \% \cdot$ decade $^{-1}$, respectively.

3.2. Cooling Effects on Stations with High Levels of Cultivated Land Use. CF $<0.2, \mathrm{CF}>0.5$, and $0.2<\mathrm{CF}<0.5$. The 49 stations with CF $>0.5$ are taken as with significant influences of agricultural development. As shown in Figure 4, the plots of temperature and moisture trends against CFs keep relatively stable after 0.5 , which was usually taken as a break value in other studies $[5,7]$. In order to isolate the impact of agricultural development from other forcing, a reference station group containing enough stations with minimal human activities is needed. Limited by the fact that the stations with minimal influences of agricultural development are less (only 10 stations are characterized with $\mathrm{CF}=0$ ), the stationaveraged trend slopes of the station group with $\mathrm{CF}<0.2$ 


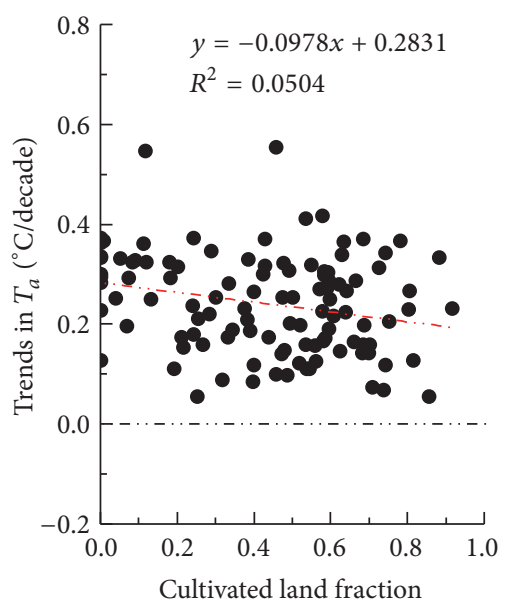

(a)

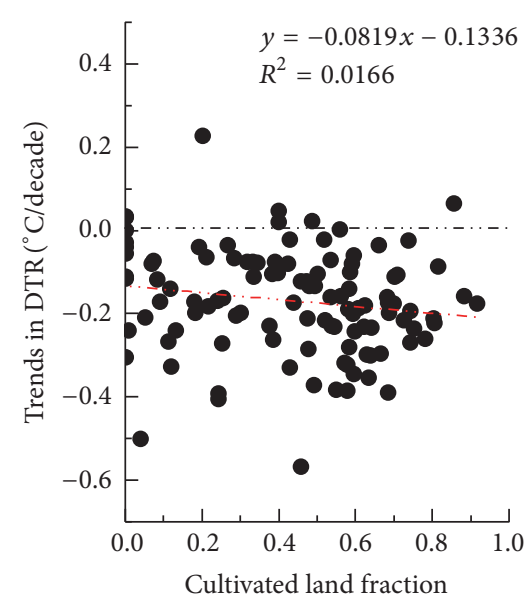

(d)

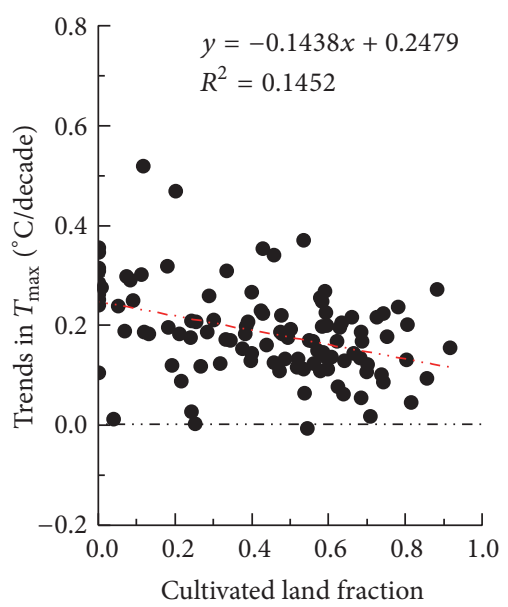

(b)

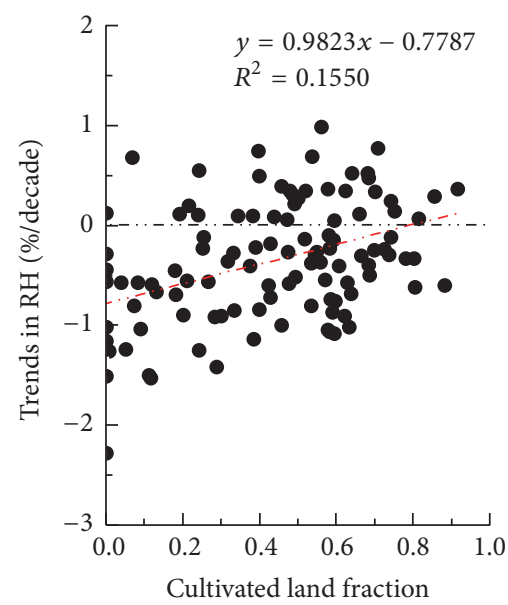

(e)

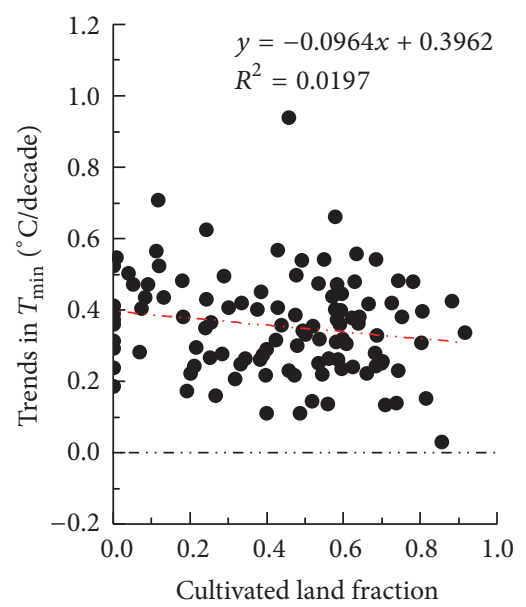

(c)

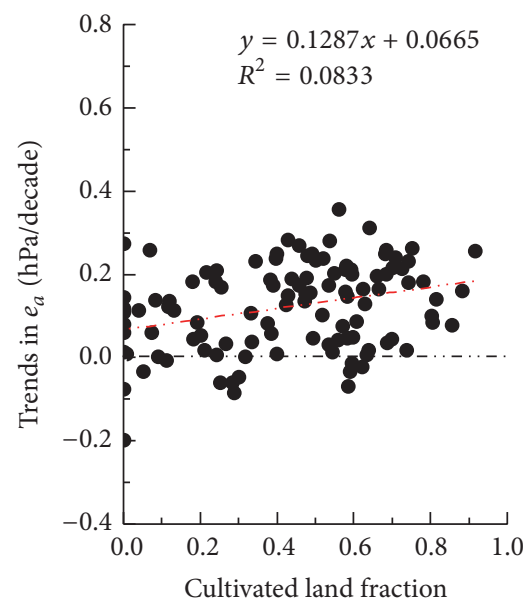

(f)

FIgure 4: Trends in May to September (a) $T_{a}$, (b) $T_{\max }$, (c) $T_{\min }$, (d) DTR, (e) RH, and (f) $e_{a}$ against the cultivated land proportion (within $3 \mathrm{~km}$ radius) of each station and their line trends (dash lines, $y=a x+b$, where $y$ is the trend in surface air temperature and $x$ is the cultivated land fractions centered at each station; $R^{2}$ is the determination coefficient).

are close to those of stations with $\mathrm{CF}=0$, and they are widely distributed in the study area. Besides, no significant statistical correlation exists between temperature trends and CFs as well as the urban land fractions. Therefore, the 23 stations with $\mathrm{CF}<0.2$ can provide a reference of background climate change, and the cooling and wetting effects of agricultural development can be detected through the comparison between the two groups in spite of their different number. The average values of May to September in terms of $T_{a}, T_{\max }$, and $T_{\min }$ trends of the station group with CF $>0.5$ are $0.225^{\circ} \mathrm{C} \cdot$ decade $^{-1}, 0.152^{\circ} \mathrm{C} \cdot$ decade $^{-1}$, and $0.336^{\circ} \mathrm{C} \cdot$ decade $^{-1}$, respectively, which are considerably smaller than those of the reference station group $\left(0.301^{\circ} \mathrm{C} \cdot\right.$ decade $^{-1}, 0.253^{\circ} \mathrm{C} \cdot$ decade $^{-1}$, and $0.410^{\circ} \mathrm{C} \cdot$ decade $^{-1}$, resp.) (Table 5). Influenced by the more significant cooling effect on $T_{\max }$ during the daytime because of enhanced evapotranspiration by agricultural development, the DTR trend of the station group with CF > 0.5 shows more significant decreasing $\left(-0.194^{\circ} \mathrm{C} \cdot\right.$ decade $\left.^{-1}\right)$ than that with $\mathrm{CF}<0.2\left(-0.145^{\circ} \mathrm{C} \cdot \mathrm{decade}^{-1}\right)$. However, the differences during the period from October to April are fairly smaller than those in the growing season.

The variations in the station-averaged growing season in terms of $T_{a}, T_{\max }, T_{\min }$, and DTR from 1960 to 2014 of the two groups are compared according to their anomalies from the means of 1960 to 1965 (Figure 5). The two station groups are characterized by similar variations; namely, a slight increase in $T_{a}, T_{\max }$, and $T_{\min }$ occurred from 1960 to the early $1990 \mathrm{~s}$, followed by a more obvious increase in 2000; and the DTR showed a slight decrease in the early 1980s. However, the station group with $\mathrm{CF}>0.5$ exhibited a less significant increase in $T_{a}, T_{\max }$, and $T_{\min }$ and a more significant decrease in DTR than the station group with CF $<0.2$, which can be easily detected from their differences. The difference has begun to increase rapidly since the late 1990s, when Northeast China began to experience a rapid agricultural development. Similar to the urban-minus-rural method used in detecting urban heat island effects [7], the cooling effects on the station group with CF $>0.5$ are determined by 
TABLE 5: Comparison of trends in growing season (May to September) and nongrowing season (October to April) $T_{a}, T_{\max }, T_{\min }$, and DTR $\left({ }^{\circ} \mathrm{C} \cdot\right.$ decade $\left.^{-1}\right), e_{a}\left(\mathrm{hPa} \cdot \mathrm{decade}^{-1}\right)$, and $\mathrm{RH}\left(\% \cdot\right.$ decade $\left.^{-1}\right)$ of station groups with cultivated land fractions larger than 0.5 and smaller than 0.2 .

\begin{tabular}{|c|c|c|c|c|c|c|c|c|c|c|c|c|c|}
\hline \multirow{2}{*}{\multicolumn{2}{|c|}{ Groups }} & \multicolumn{6}{|c|}{ Growing season } & \multicolumn{6}{|c|}{ Nongrowing season } \\
\hline & & $T_{a}$ & $T_{\max }$ & $T_{\min }$ & DTR & $e_{a}$ & $\mathrm{RH}$ & $T_{a}$ & $T_{\max }$ & $T_{\min }$ & DTR & $e_{a}$ & $\mathrm{RH}$ \\
\hline \multirow{3}{*}{$\mathrm{I}^{\mathrm{a}}$} & $\mathrm{CF}<0.2$ & 0.301 & 0.253 & 0.410 & -0.145 & 0.077 & -0.801 & 0.365 & 0.231 & 0.505 & -0.279 & 0.045 & -0.528 \\
\hline & $\mathrm{CF}>0.5$ & 0.225 & 0.152 & 0.336 & -0.194 & 0.141 & -0.196 & 0.345 & 0.194 & 0.497 & -0.305 & 0.056 & -0.187 \\
\hline & ifference & -0.076 & -0.101 & -0.074 & -0.049 & 0.064 & 0.605 & -0.020 & -0.037 & -0.008 & -0.026 & 0.011 & 0.341 \\
\hline & $\mathrm{CF}<0.2$ & 0.294 & 0.229 & 0.396 & -0.140 & 0.067 & -0.765 & 0.388 & 0.234 & 0.513 & -0.289 & 0.004 & -0.482 \\
\hline & $\mathrm{CF}>0.5$ & 0.226 & 0.148 & 0.327 & -0.192 & 0.142 & -0.205 & 0.354 & 0.196 & 0.503 & -0.282 & 0.005 & -0.159 \\
\hline & ifference & -0.067 & -0.081 & -0.069 & -0.052 & 0.075 & 0.560 & -0.034 & -0.039 & -0.010 & 0.007 & 0.001 & 0.323 \\
\hline
\end{tabular}

${ }^{\mathrm{a}}$ Arithmetic mean of the trend slopes of all stations in the group.

${ }^{b}$ Calculating the station-averaged temperature time series from 1960 to 2014 first and then calculating the trend slope of the time series.

${ }^{*}$ Computed by subtracting value of station group with $\mathrm{CF}<0.2$ from that of group with $\mathrm{CF}>0.5$.

evaluating the differences in temperature trends with the reference station group with $\mathrm{CF}<0.2 . T_{a}, T_{\max }, T_{\min }$, and DTR in the growing season from 1960 to 2014 of the station group with $\mathrm{CF}>0.5$ had slowly declined by approximately $-0.067^{\circ} \mathrm{C} \cdot$ decade $^{-1},-0.081^{\circ} \mathrm{C} \cdot$ decade $^{-1},-0.069^{\circ} \mathrm{C} \cdot$ decade $^{-1}$, and $-0.052^{\circ} \mathrm{C} \cdot$ decade $^{-1}$ with respect to the reference station group (Table 5).

3.3. Wetting Effects on Stations with High Levels of Cultivated Land Use. The atmospheric moisture for the stations with $\mathrm{CF}>0.5$ is apparently higher than that for the reference group $\mathrm{CF}<0.2$. The trends in the growing season in terms of $e_{a}$ and $\mathrm{RH}$ of the station group with CF $>0.5$ are $0.141 \mathrm{hPa} \cdot$ decade $^{-1}$ and $-0.196 \% \cdot$ decade $^{-1}$, respectively, whereas those of the reference group are only $0.077 \mathrm{hPa} \cdot$ decade $^{-1}$ and $-0.801 \% \cdot$ decade $^{-1}$, respectively (Table 5). The differences in the station-averaged data from October to April in terms of $e_{a}$ and $\mathrm{RH}$ between the two groups $\left(0.011 \mathrm{hPa} \cdot \mathrm{decade}^{-1}\right.$ and $0.341 \% \cdot$ decade $\left.^{-1}\right)$ are fairly smaller than those in the growing season $\left(0.064 \mathrm{hPa} \cdot\right.$ decade $^{-1}$ and $0.605 \% \cdot$ decade $^{-1}$ ).

The anomalies in the station-averaged near-surface $e_{a}$ and $\mathrm{RH}$ during the growing season of the two groups are compared in Figure 5. The averaged $e_{a}$ increases while $\mathrm{RH}$ decreases during 1960-2014, which ought to be caused by the significant warming over the study area. According to (1), the significant warming has enlarged the saturation vapor pressure, as well as $e_{a}$, although the increasing amount is smaller than the saturation vapor pressure with decreasing $\mathrm{RH}$. The averaged $e_{a}$ of stations with $\mathrm{CF}<0.2$ showed a minor upward trend overall, with a large decrease from 1960 to 1969 , followed by a slight increase from 1970s to 2000, and then a small decrease until 2009. Compared with the reference group, the averaged $e_{a}$ of stations with $\mathrm{CF}>0.5$ presented an apparent increase after the 1980s, reflecting a more significant atmospheric wetting. The near-surface $\mathrm{RH}$ of the two groups had shown a slight decrease from 1960 to 2014. However, the averaged RH of stations with CF > 0.5 exhibited a less significant decrease than that of stations with $\mathrm{CF}<0.2$, the difference of which had enlarged since the late 1990s. According to the difference in the trends in station-averaged data regarding $e_{a}$ and $\mathrm{RH}$, the wetting effects on the station group with $\mathrm{CF}>0.5$ resulted in an increase on $e_{a}$ with $0.075 \mathrm{hPa} \cdot$ decade $^{-1}$ and an increase on $\mathrm{RH}$ with $0.560 \% \cdot$ decade $^{-1}$ from 1960 to 2014 in Northeast China (Table 5).

\section{Discussion}

In Northeast China, the temperature trends during the growing season are significantly negatively correlated with the CFs of meteorological stations, whereas the near-surface atmospheric content trends are significantly positively correlated with the CFs. Nevertheless, most of the cultivated land distributes on the middle region with low elevation, making the CFs of stations negatively correlate with altitude and leaving a possibility that the dependence of temperature trends and atmospheric content trends on the CFs comes from the geographic locations of stations. No significant correlations exist between the CFs and the longitude of stations (the correlation coefficient is 0.13 ), and the correlation between the CFs and the latitude of stations is weaker than that between the CFs and the temperature and moisture content trends. Although the CFs of stations are significantly correlated with altitude (correlation coefficient is -0.51 ), the trends in temperature and atmospheric moisture content at stations with $\mathrm{CF}>0.5$ for all 78 stations with elevation between 90 and $700 \mathrm{~m}$ (39 stations, with the average growing season trend slope of $0.241,0.163$, and $0.353^{\circ} \mathrm{C} \cdot$ decade $^{-1}$ for $T_{a}, T_{\max }$, and $T_{\min }$, resp., as well as $0.129 \mathrm{hPa} \cdot \mathrm{decade}^{-1}$ and $-0.291 \% \cdot$ decade $^{-1}$ for $e_{a}$ and $\mathrm{RH}$ ) remain more significant than those at stations with $\mathrm{CF}<0.2$ (13 stations, with the average growing season trend slope of $0.305,0.248$, and $0.435^{\circ} \mathrm{C} \cdot$ decade $^{-1}$ for $T_{a}, T_{\max }$, and $T_{\min }$, resp., as well as $0.104 \mathrm{hPa} \cdot \mathrm{decade}^{-1}$ and $-0.729 \% \cdot$ decade $^{-1}$ for $e_{a}$ and $\left.\mathrm{RH}\right)$. However, the difference in elevation (average values are 247 and $340 \mathrm{~m}$ ) is negligible. Besides, the 23 reference stations with $\mathrm{CF}<0.2$ are widely distributed in the study area $\left(116^{\circ} 7^{\prime} \mathrm{E}\right.$ to $129^{\circ} 36^{\prime} \mathrm{E}, 38^{\circ} 54^{\prime} \mathrm{N}$ to $50^{\circ} 29^{\prime} \mathrm{N}$, and an altitude from 91.5 to $1003 \mathrm{~m}$ ), and no correlation exists between the trends and the locations of these stations. These findings suggest that the geographic locations of stations have a minimal effect or no effect on the relationship among the trends in temperature, $e_{a}, \mathrm{RH}$, and CFs during the growing season. 


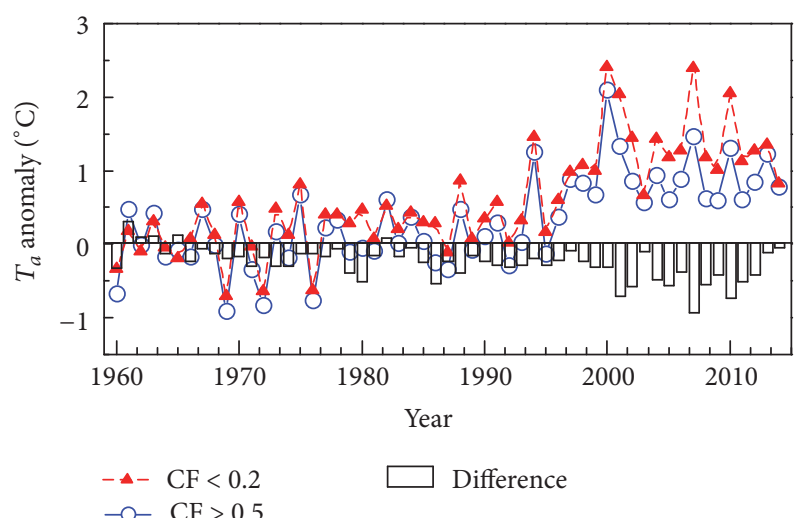

(a)

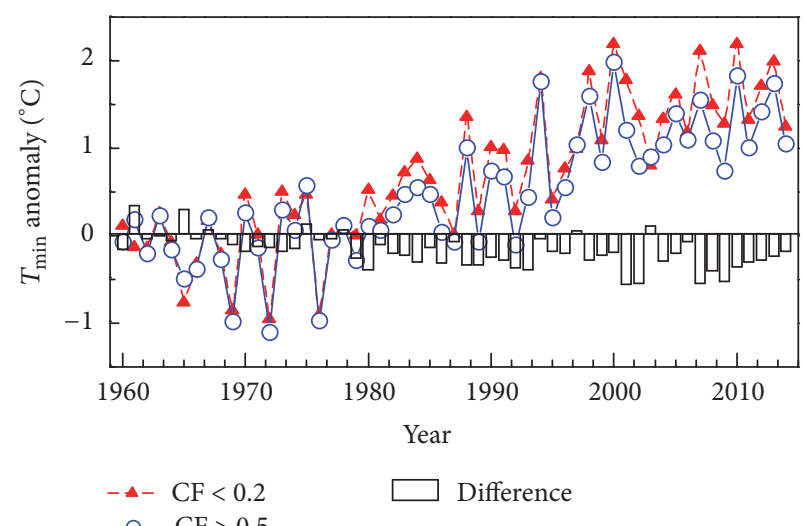

(c)

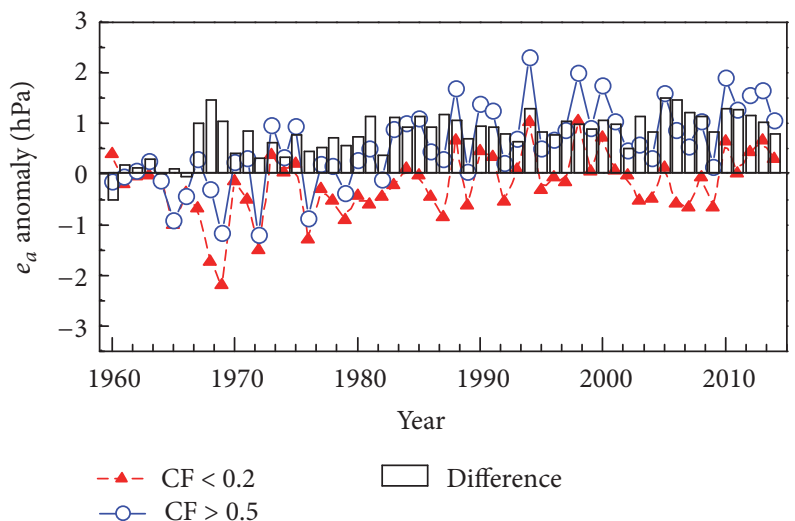

(e)

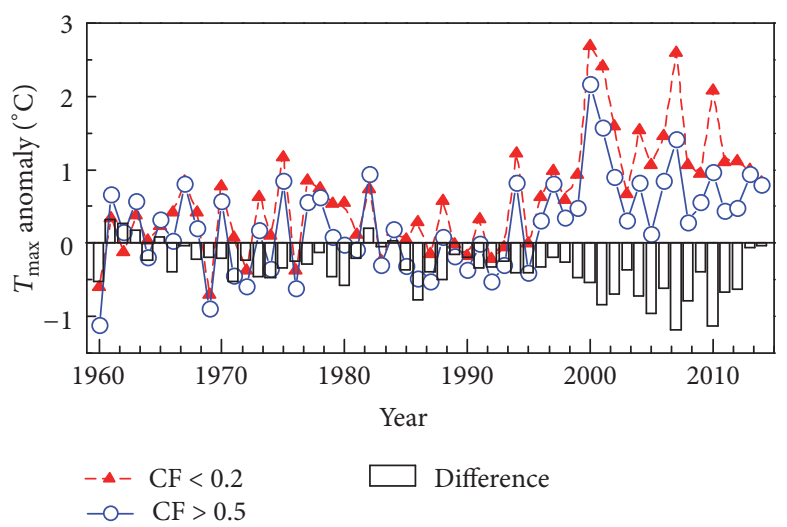

(b)

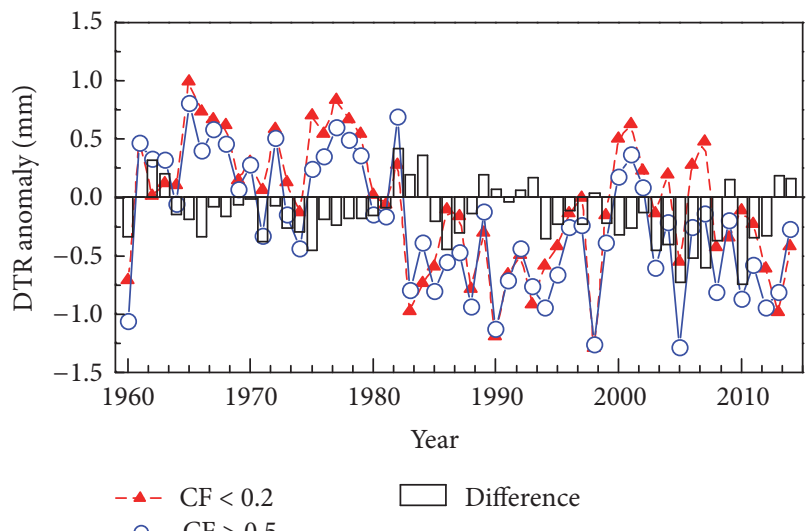

(d)

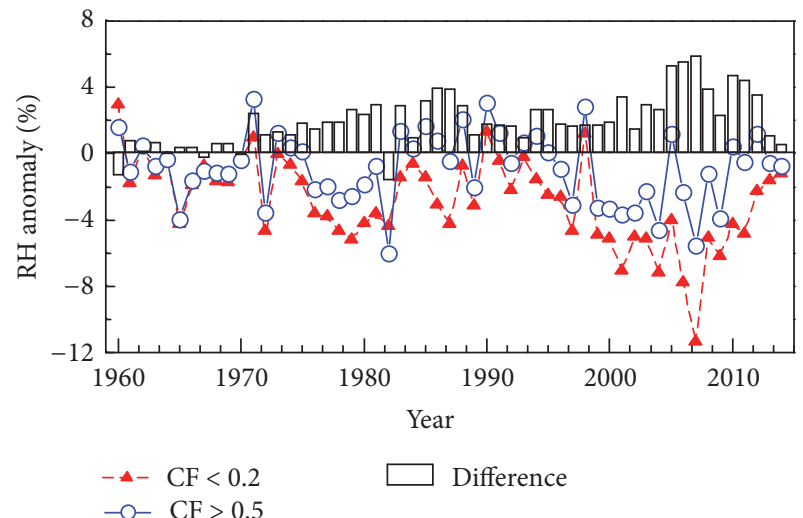

(f)

FIGURE 5: Time series of station-averaged growing season (a) $T_{a}$, (b) $T_{\max }$, (c) $T_{\min }$, (d) DTR, (e) $e_{a}$, and (f) RH anomaly from the means of 1960-1965 of the station groups with CF $<0.2$ and CF $>0.5$ from 1960 to 2014 and differences between the two groups (bars).

Other topographic factors, such as the terrain slope and aspect, were not considered in the analysis as most stations in the study area are located in the plain.

From 1960 to 2014, Northeast China had experienced a rapid agriculture development (Figure 2). Accordingly, the land uses surrounding the stations with large CFs would be significantly affected in the growing season, which can be detected from the normalized difference vegetation index (NDVI) of the pixel where the stations are located; it is calculated from the biweekly NDVI data of 1982 to 2011 obtained from the third-generation Global Inventory Monitoring and Modeling Studies-NDVI3g database [55], with a spatial resolution of $8 \mathrm{~km}$. The differences in the average yearly mean NDVI at the pixel where the stations are located between the station groups $\mathrm{CF}>0.5$ and $\mathrm{CF}<0.2$ from 1982 to 2011 are compared in Figure 6. The land surrounding the stations with CF $>0.5$ had experienced relatively obvious increasing vegetation activities in the growing season compared with the stations with $\mathrm{CF}<0.2$. By contrast, a weak declining trend in the difference in the average yearly mean 


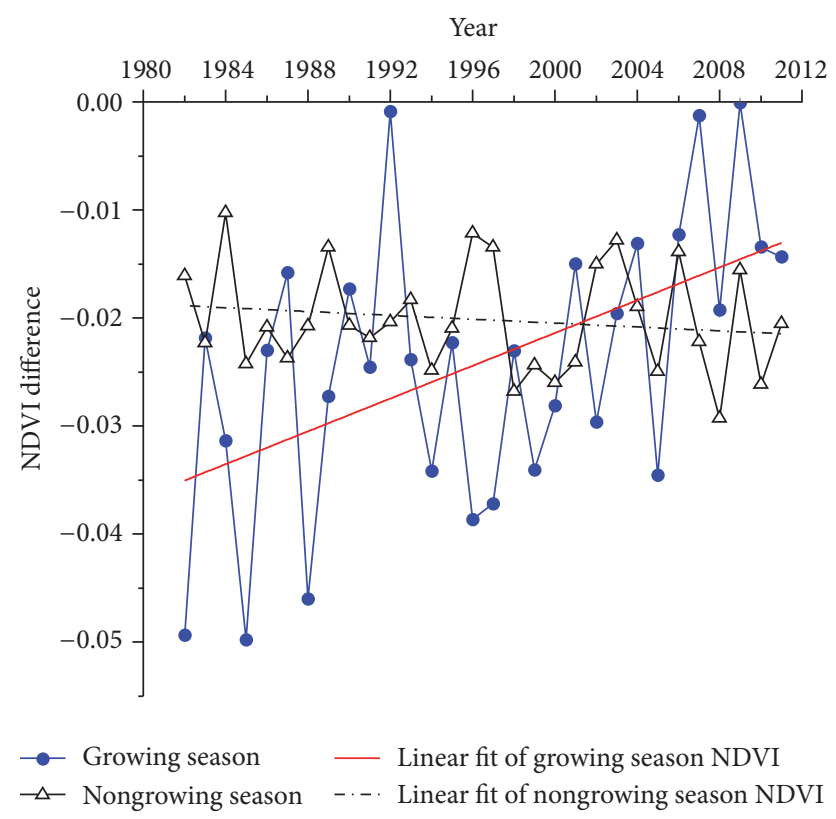

Figure 6: Differences of average yearly mean NDVI between stations with $\mathrm{CF}>0.5$ and $\mathrm{CF}<0.2$ in growing season and nongrowing season. The solid line represents the variation trend of growing season NDVI, and the dash line is for the nongrowing season NDVI trend.

NDVI in the nongrowing season existed. The difference in NDVI in the growing season is highly negatively correlated with the differences in $T_{a}, T_{\max }$, and $T_{\min }$ (the correlation coefficients are $-0.50,-0.40$, and -0.39 , resp., with $P<$ $0.05)$ but is positively correlated with the difference in $e_{a}$ and $\mathrm{RH}$ (the correlation coefficients are 0.18 and 0.43 , resp., with $P<0.05)$. Meanwhile, no significant correlation exists between precipitation trends and CFs, and no obvious difference is identified in the variation of annual precipitation between the two groups. Therefore, the cooling and wetting effects on the stations with CF $>0.5$ in Northeast China would be potentially attributed to the agricultural development of the areas surrounding these stations. However, the mechanism of agricultural development-induced cooling and wetting effects is usually complicated; whether it is dominated by direct evaporation cooling or indirect effects, such as increase in cloud cover in Northeast China, should be further detected.

According to pairwise comparisons, the agricultural development from 1960 to 2014 is associated with cooling effect on $T_{\max }$ from May to September for stations with $\mathrm{CF}>0.5$ by $-0.081^{\circ} \mathrm{C} \cdot$ decade $^{-1}$, the magnitude of which is $35.4 \%$ of the trend slope of the reference station group $\left(0.229^{\circ} \mathrm{C} \cdot\right.$ decade $\left.^{-1}\right)$, indicating that the warming for the station group with $\mathrm{CF}>0.5$ has been reduced by $35.4 \%$, compared with the warming of the reference group when regarding it as natural climate variability. The cooling effects on $T_{a}$ and $T_{\min }$ during the growing season $\left(-0.067^{\circ} \mathrm{C}\right.$ and $-0.069^{\circ} \mathrm{C} \cdot$ decade $^{-1}$, the magnitude of which are $22.8 \%$ and $17.4 \%$ of the trend slope of the reference station group, resp.) are smaller than that of $T_{\max }$.
Accompanied with cooling, agricultural development is associated with the wetting of $e_{a}$ from May to September and RH by approximately $0.064 \mathrm{hPa} \cdot \mathrm{decade}^{-1}$ and $0.605 \% \cdot$ decade $^{-1}$, respectively. Our result on cooling effects agrees with the results reported by Zhu et al. [43], in which the difference in the trends of $T_{\max }$ from 1956 to 2008 between two highly and lightly irrigated sites in the Jilin province is $0.085^{\circ} \mathrm{C} \cdot$ decade $^{-1}$. However, the cooling effects are lower than those in Northwest and North Plain of China with intensive irrigation. In Xinjiang, Northwest China, the irrigation expansion from 1959 to 2006 is associated with the cooling of $T_{a}, T_{\max }$, and $T_{\min }$ from May to September by $-0.148,-0.119$, and $-0.138^{\circ} \mathrm{C} \cdot$ decade $^{-1}$, respectively, in the station group with extensive irrigation [7]. In the HuangHuai-Hai Plain of China, irrigation indicated a cooling effect of $0.12^{\circ} \mathrm{C} \cdot$ decade $^{-1}$ on summertime daily maximum temperature [34]. In California, USA, the irrigation expansion from June to August leads to the fact that the current irrigation level exceeds $50 \%$, and the summer $T_{\max }$ decreased by $-0.14^{\circ} \mathrm{C}$ to $-0.25^{\circ} \mathrm{C} \cdot$ decade $^{-1}$ from 1915 to 1979 owing to irrigation [25]. Irrigation expansion is an important aspect of agricultural development that is at the origin of cooling and wetting effects [5]. The lower irrigation intensity in Northeast China (the irrigated area is only $35.9 \%$ of the total sown area in 2014) may be one of the reasons for its lower cooling effect than above regions. However, the present irrigation project with water-saving technologies in Northeast China, by which the newly increase of irrigated area is approximately $30 \%$ of that in 2013, would result in further cooling and wetting effects in these agricultural regions, which could have positive effects on agriculture. However, given that the irrigation amount per unit area with water-saving technologies is less than that with flood irrigation, the cooling and wetting effects of irrigation will therefore likely be different in the future than in the past century. However, further studies are needed.

Specific uncertainties associated with this study should also be noted. Only the land use data for year 2000 are used in this study because of data shortage, which may lead to uncertainties illustrated in Figure 4. According to Lobell and Bonfils [25], the spatial distributions of cultivated lands, types of crops grown, or irrigation methods used could cause differences among stations with similar CFs. Urban land uses may also affect the atmospheric moisture, clouds, and precipitation. These factors are not considered in the present study, although stations with an urban land fraction larger than $25 \%$ within a $3 \mathrm{~km}$ radius are excluded to eliminate the influence of urban land uses. More observations and temporal information are needed for further understanding of the cooling and wetting effects of agricultural irrigation in Northeast China. Furthermore, we should pay attention to how land cover dynamics, types of crops growth, and especially irrigation interact with climate, as well as the magnitude of this interaction.

\section{Conclusions}

The preceding analysis demonstrates that observations of near-surface atmospheric temperature and moisture in 
Northeast China were disturbed by agricultural development. Stations surrounded with large fractions of cultivated land experienced less rapid increases in air temperature, more rapid increases in water vapor pressure, and weak decreases in $\mathrm{RH}$ from 1960 to 2014. Compared with the average $T_{a}$, $T_{\max }$, and $T_{\min }$, as well as $e_{a}$ and $\mathrm{RH}$, of 23 stations with $\mathrm{CF}<0.2$, those values of 49 stations with $\mathrm{CF}>0.5$ exhibited cooling of $-0.067,-0.081$, and $-0.069^{\circ} \mathrm{C} \cdot$ decade $^{-1}$ and wetting of $0.075 \mathrm{hPa} \cdot$ decade $^{-1}$ and $0.56 \% \cdot$ decade $^{-1}$. The difference was associated with agricultural development. In light of this scenario, the agricultural development introduces excessive cooling and wetting signals to the observations in Northeast China. The agricultural development around meteorological stations should be seriously considered for a better understanding of observed near-surface atmospheric temperature and moisture. However, special uncertainties, such as the spatial distributions of cultivated lands, types of crops grown, or irrigation methods, still need to be further noted.

\section{Competing Interests}

The authors declare that they have no competing interests.

\section{Acknowledgments}

This research was partially sponsored by the National Key Technology R\&D Program (2014BAD12B05), the National Natural Science Foundation of China (no. 51579249), the Research Fund (no. 2016ZY06) and Open Research Fund (no. IWHR-SKL-201612) of State Key Laboratory of Simulation and Regulation of Water Cycle in River Basin, China Institute of Water Resources and Hydropower Research, and the National Nonprofit Institute Research Grant from CAFINT (Grant no. CAFINT2015K06).

\section{References}

[1] J. Fang, S. Piao, J. He, and W. Ma, "Increasing terrestrial vegetation activity in China, 1982-1999," Science in China, Series C: Life Sciences, vol. 47, no. 3, pp. 229-240, 2004.

[2] O. Boucher, G. Myhre, and A. Myhre, "Direct human influence of irrigation on atmospheric water vapour and climate," Climate Dynamics, vol. 22, no. 6-7, pp. 597-603, 2004.

[3] J. Xiao and A. Moody, "Trends in vegetation activity and their climatic correlates: China 1982 to 1998," International Journal of Remote Sensing, vol. 25, no. 24, pp. 5669-5689, 2004.

[4] Q. Tang, E. R. Vivoni, F. MuñOz-Arriola, and D. P. Lettenmaier, "Predictability of evapotranspiration patterns using remotely sensed vegetation dynamics during the North American Monsoon," Journal of Hydrometeorology, vol. 13, no. 1, pp. 103-121, 2012.

[5] C. Bonfils and D. Lobell, "Empirical evidence for a recent slowdown in irrigation-induced cooling," Proceedings of the National Academy of Sciences of the United States of America, vol. 104, no. 34, pp. 13582-13587, 2007.

[6] X. Zhang, Q. Tang, J. Zheng, and Q. Ge, "Warming/cooling effects of cropland greenness changes during 1982-2006 in the North China Plain," Environmental Research Letters, vol. 8, no. 2, Article ID 024038, 2013.
[7] S. Han and Z. Yang, "Cooling effect of agricultural irrigation over Xinjiang, Northwest China from 1959 to 2006," Environmental Research Letters, vol. 8, no. 2, Article ID 024039, 2013.

[8] M. Guimberteau, K. Laval, A. Perrier, and J. Polcher, "Global effect of irrigation and its impact on the onset of the Indian summer monsoon," Climate Dynamics, vol. 39, no. 6, pp. 13291348, 2012.

[9] E.-S. Im, M. P. Marcella, and E. A. B. Eltahir, "Impact of potential large-scale irrigation on the West African monsoon and its dependence on location of irrigated area," Journal of Climate, vol. 27, no. 3, pp. 994-1009, 2014.

[10] S. M. Asokan and G. Destouni, "Irrigation effects on hydroclimatic change: basin-wise water balance-constrained quantification and cross-regional comparison," Surveys in Geophysics, vol. 35, no. 3, pp. 879-895, 2014.

[11] G. Leng, M. Huang, Q. Tang, W. J. Sacks, H. Lei, and L. R. Leung, "Modeling the effects of irrigation on land surface fluxes and states over the conterminous United States: sensitivity to input data and model parameters," Journal of Geophysical Research: Atmospheres, vol. 118, no. 17, pp. 9789-9803, 2013.

[12] Q. Tang, T. Oki, S. Kanae, and H. Hu, "Hydrological cycles change in the Yellow River basin during the last half of the twentieth century," Journal of Climate, vol. 21, no. 8, pp. 17901806, 2008.

[13] H. Lei, D. Yang, H. Yang, Z. Yuan, and H. Lv, "Simulated impacts of irrigation on evapotranspiration in a strongly exploited region: a case study of the Haihe River basin, China," Hydrological Processes, vol. 29, no. 12, pp. 2704-2719, 2015.

[14] M.-H. Lo and J. S. Famiglietti, "Irrigation in California's Central Valley strengthens the southwestern U.S. water cycle," Geophysical Research Letters, vol. 40, no. 2, pp. 301-306, 2013.

[15] Y. Lu and L. Kueppers, "Increased heat waves with loss of irrigation in the United States," Environmental Research Letters, vol. 10, no. 6, Article ID 064010, 2015.

[16] N. D. Mueller, E. E. Butler, K. A. McKinnon et al., "Cooling of US Midwest summer temperature extremes from cropland intensification," Nature Climate Change, vol. 6, no. 3, pp. 317322, 2015

[17] R. Mahmood, K. G. Hubbard, R. D. Leeper, and S. A. Foster, "Increase in near-surface atmospheric moisture content due to land use changes: evidence from the observed dewpoint temperature data," Monthly Weather Review, vol. 136, no. 4, pp. $1554-1561,2008$

[18] Y. Qian, M. Huang, B. Yang, and L. K. Berg, "A modeling study of irrigation effects on surface fluxes and land-aircloud interactions in the southern great plains," Journal of Hydrometeorology, vol. 14, no. 3, pp. 700-721, 2013.

[19] H. Kawase, T. Yoshikane, M. Hara, F. Kimura, T. Sato, and S. Ohsawa, "Impact of extensive irrigation on the formation of cumulus clouds," Geophysical Research Letters, vol. 35, no. 1, Article ID L01806, 2008.

[20] J. Wei, P. A. Dirmeyer, D. Wisser, M. G. Bosilovich, and D. M. Mocko, "Where does the irrigation water go? An estimate of the contribution of irrigation to precipitation using MERRA," Journal of Hydrometeorology, vol. 14, no. 1, pp. 275-289, 2013.

[21] Y. Zhao, Y. J. Fang, C. X. Cui, and A. N. Huang, "Effects of irrigation on precipitation in the arid regions of Xinjiang, China," Journal of Arid Land, vol. 4, no. 2, pp. 132-139, 2012.

[22] G. B. Bonan, "Observational evidence for reduction of daily maximum temperature by Croplands in the Midwest United States," Journal of Climate, vol. 14, no. 11, pp. 2430-2442, 2001. 
[23] J. O. Adegoke, R. A. Pielke Sr., J. Eastman, R. Mahmood, and K. G. Hubbard, "Impact of irrigation on midsummer surface fluxes and temperature under dry synoptic conditions: a regional atmospheric model study of the U.S. high plains," Monthly Weather Review, vol. 131, no. 3, pp. 556-564, 2003.

[24] B. Govindasamy, P. B. Duffy, and K. Caldeira, "Land use changes and Northern Hemisphere cooling," Geophysical Research Letters, vol. 28, no. 2, pp. 291-294, 2001.

[25] D. B. Lobell and C. Bonfils, "The effect of irrigation on regional temperatures: a spatial and temporal analysis of trends in California, 1934-2002," Journal of Climate, vol. 21, no. 10, pp. 2063-2071, 2008.

[26] M. J. Puma and B. I. Cook, "Effects of irrigation on global climate during the 20th century," Journal of Geophysical Research: Atmospheres, vol. 115, no. 16, Article ID D16120, 2010.

[27] Z. Jianping, Y. Zhong, W. Daojie, and Z. Xinbao, "Climate change and causes in the Yuanmou dry-hot valley of Yunnan, China," Journal of Arid Environments, vol. 51, no. 1, pp. 153-162, 2002.

[28] D. J. Gaffen and R. J. Ross, "Climatology and trends of U.S. surface humidity and temperature," Journal of Climate, vol. 12, no. 2-3, pp. 811-828, 1999.

[29] R. Mahmood, K. G. Hubbard, and C. Carlson, "Modification of growing-season surface temperature records in the northern great plains due to land-use transformation: verification of modelling results and implication for global climate change," International Journal of Climatology, vol. 24, no. 3, pp. 311-327, 2004.

[30] E. E. Perkins, "Irrigation controls on atmospheric water vapor, Southern India," in Geography, Watershed Science, San Diego State University, 2012.

[31] S. Han, Q. Tang, D. Xu, S. Wang, and Z. Yang, "Observed nearsurface atmospheric moisture content changes affected by irrigation development in Xinjiang, Northwest China," Theoretical and Applied Climatology, pp. 1-11, 2016.

[32] L. Jiang, E. Ma, and X. Deng, "Impacts of irrigation on the heat fluxes and near-surface temperature in an inland irrigation area of Northern China," Energies, vol. 7, no. 3, pp. 1300-1317, 2014.

[33] L. Xu, Z. Shi, Y. Wang et al., "Agricultural irrigation-induced climatic effects: a case study in the middle and southern Loess Plateau area, China," International Journal of Climatology, 2016.

[34] W. Shi, F. Tao, and J. Liu, "Regional temperature change over the Huang-Huai-Hai Plain of China: the roles of irrigation versus urbanization," International Journal of Climatology, vol. 34, no. 4, pp. 1181-1195, 2014.

[35] B. Yang, Y. Zhang, Y. Qian, J. Tang, and D. Liu, "Climatic effects of irrigation over the Huang-Huai-Hai Plain in China simulated by the weather research and forecasting model," Journal of Geophysical Research: Atmospheres, vol. 121, no. 5, pp. 22462264, 2016.

[36] X. Zhang, W.-C. Wang, X. Fang, Y. Ye, and J. Zheng, "Agriculture development-induced surface albedo changes and climatic implications across northeastern China," Chinese Geographical Science, vol. 22, no. 3, pp. 264-277, 2012.

[37] C. Chen, C. Lei, A. Deng, C. Qian, W. Hoogmoed, and W. Zhang, "Will higher minimum temperatures increase corn production in Northeast China? An analysis of historical data over 1965-2008," Agricultural and Forest Meteorology, vol. 151, no. 12, pp. 1580-1588, 2011.

[38] J. Gao and Y. Liu, "Climate warming and land use change in Heilongjiang Province, Northeast China," Applied Geography, vol. 31, no. 2, pp. 476-482, 2011.
[39] D. Jhajharia, Y. Dinpashoh, E. Kahya, R. R. Choudhary, and V. P. Singh, "Trends in temperature over Godavari River basin in Southern Peninsular India," International Journal of Climatology, vol. 34, no. 5, pp. 1369-1384, 2014.

[40] G. Ren and Y. Wang, "Climate change of Northeast China over the past 50 years," Journal of Arid Land Resources and Environment, vol. 23, pp. 25-30, 2009.

[41] Y. Liu, D. Wang, J. Gao, and W. Deng, "Land use/cover changes, the environment and water resources in Northeast China," Environmental Management, vol. 36, no. 5, pp. 691-701, 2005.

[42] Z. Chunyu, R. Guoyu, Z. YunFu, and W. Ying, "Climate change in northeast China over the past 50 years," Journal of Arid Land Resources and Environment, vol. 23, no. 7, pp. 25-30, 2009.

[43] X. Zhu, S. Liang, and Y. Pan, "Observational evidence of the cooling effect of agricultural irrigation in Jilin, China," Climatic Change, vol. 114, no. 3-4, pp. 799-811, 2012.

[44] L. Liang, L. Li, and Q. Liu, "Precipitation variability in Northeast China from 1961 to 2008," Journal of Hydrology, vol. 404, no. 1-2, pp. 67-76, 2011.

[45] X. Wang, L. Peng, X. Zhang, G. Yin, C. Zhao, and S. Piao, "Divergence of climate impacts on maize yield in Northeast China," Agriculture, Ecosystems \& Environment, vol. 196, pp. 5158, 2014.

[46] Q. S. Li, L. S. Willardson, W. Deng, X. J. Li, and C. J. Liu, "Crop water deficit estimation and irrigation scheduling in western Jilin province, Northeast China," Agricultural Water Management, vol. 71, no. 1, pp. 47-60, 2005.

[47] G. Yin, Z. Kang, J. Gu, L. Hao, P. Cong, and Z. Liu, "Deficit irrigation scheduling of maize in the semi-arid area of northeast China," Journal of Food, Agriculture and Environment, vol. 11, no. 2, pp. 1035-1039, 2013.

[48] R. G. Allen, L. S. Pereira, D. Raes, and M. Smith, Crop Evapotranspiration-Guidelines for Computing Crop Water Requirements-FAO Irrigation and Drainage Paper 56, vol. 300, no. 9, FAO-Food and Agriculture Organization of the United Nations, Rome, Italy, 1998.

[49] J. Liu, M. Liu, D. Zhuang, Z. Zhang, and X. Deng, "Study on spatial pattern of land-use change in China during 1995-2000," Science in China Series D: Earth Sciences, vol. 46, no. 4, pp. 373384, 2003.

[50] Y. Liu, L. Wang, G. Ni, and Z. Cong, "Spatial distribution characteristics of irrigation water requirement for main crops in China," Transactions of the Chinese Society of Agricultural Engineering, vol. 25, no. 12, pp. 6-12, 2009.

[51] D. Jhajharia and V. P. Singh, "Trends in temperature, diurnal temperature range and sunshine duration in Northeast India," International Journal of Climatology, vol. 31, no. 9, pp. 1353-1367, 2011.

[52] S. Yue, P. Pilon, B. Phinney, and G. Cavadias, "The influence of autocorrelation on the ability to detect trend in hydrological series," Hydrological Processes, vol. 16, no. 9, pp. 1807-1829, 2002.

[53] D. Jhajharia, S. K. Shrivastava, D. Sarkar, and S. Sarkar, “Temporal characteristics of pan evaporation trends under the humid conditions of northeast India," Agricultural and Forest Meteorology, vol. 149, no. 5, pp. 763-770, 2009.

[54] S. Han, D. Xu, and S. Wang, "Decreasing potential evaporation trends in China from 1956 to 2005: accelerated in regions with significant agricultural influence?" Agricultural and Forest Meteorology, vol. 154-155, pp. 44-56, 2012.

[55] J. E. Pinzon and C. J. Tucker, "A non-stationary 1981-2012 AVHRR NDVI3g time series," Remote Sensing, vol. 6, no. 8, pp. 6929-6960, 2014. 

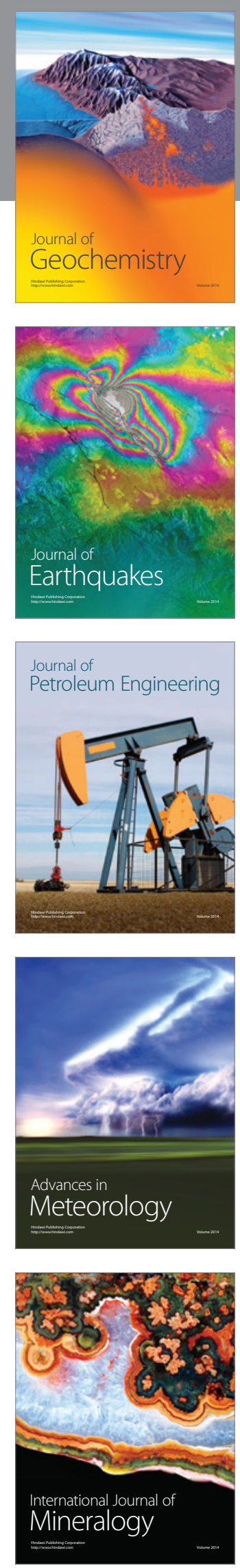
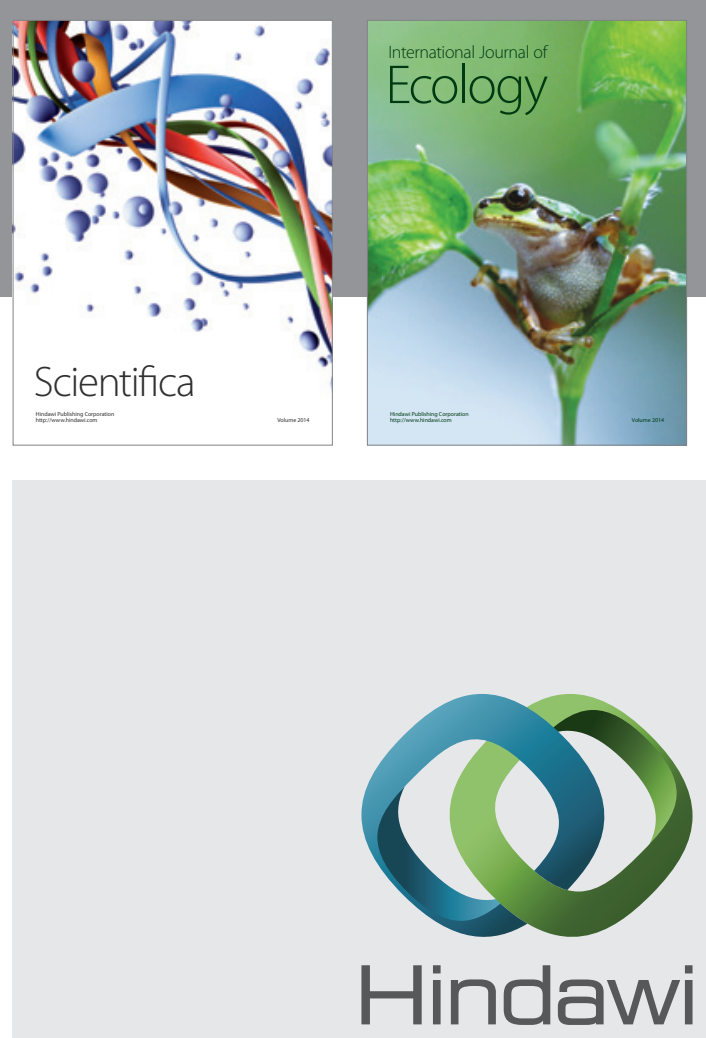

Submit your manuscripts at

http://www.hindawi.com
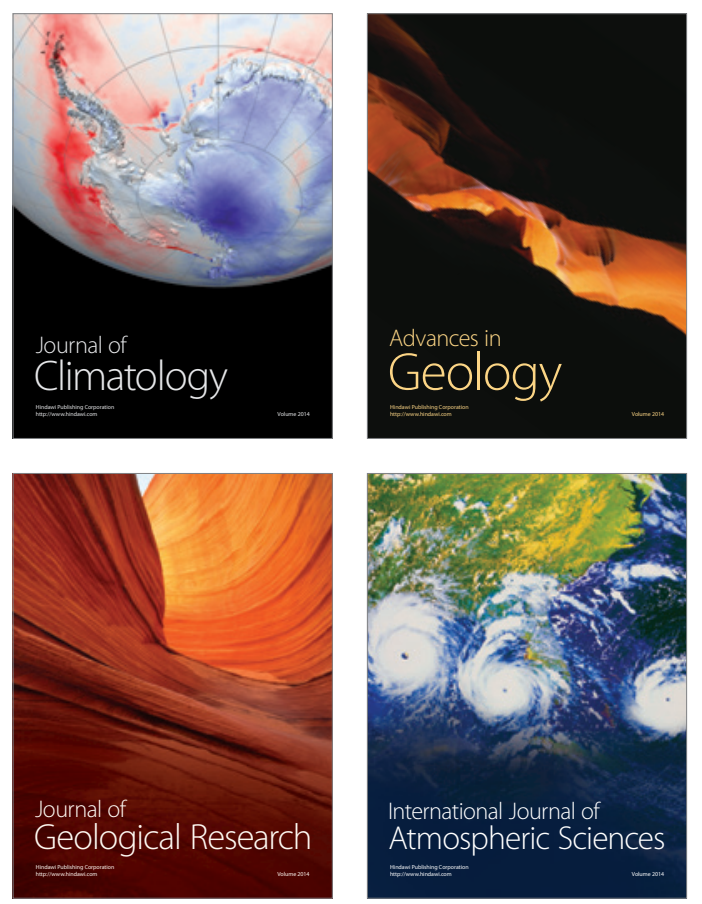

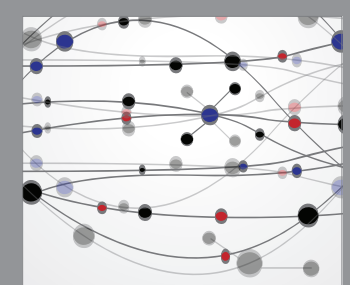

The Scientific

\section{World Journal}
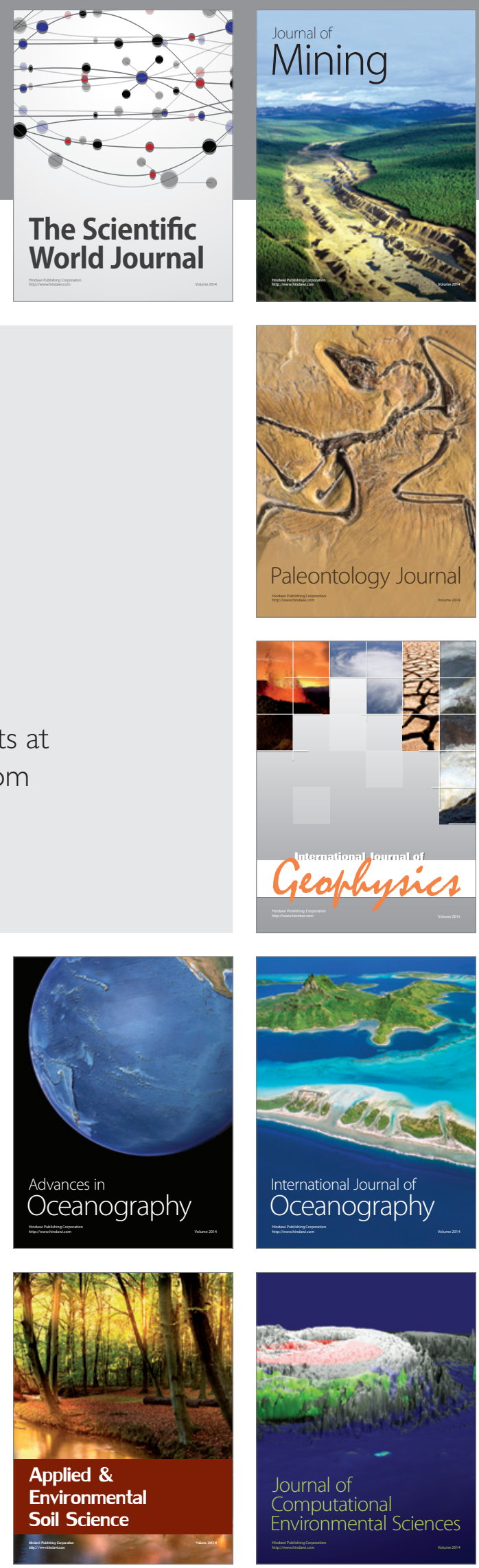